\title{
IP-for-IP or Cash-for-IP? R\&D Competition and the Market for Technology
}

\author{
Patrick Herbst ${ }^{1}$ (D) Eric Jahn $^{2}$
}

Published online: 17 September 2016

(C) The Author(s) 2016. This article is published with open access at Springerlink.com

\begin{abstract}
We analyze how firms might benefit from trading restrictions in the market for technology. We show that restricting trade to reciprocal exchange ("IPfor-IP" barter instead of cash transactions), as in cross-licensing agreements, alters the allocation of $R \& D$ resources and reduces overinvestment in $R \& D$. The tighter are the trading restrictions, the higher are the costs that are due to forgone gains from trade. Our analysis of the trade-offs involved shows that firms benefit from IPfor-IP restrictions, compared to both free trade and no trade environments, in industries where: (1) firms differ in their capabilities to commercialize IP; and (2) patent complementarities exist.
\end{abstract}

Keywords Intellectual property $\cdot$ R\&D competition · IP-for-IP · Cross-licensing · Technology trade

JEL Classification $\mathrm{O} 32 \cdot \mathrm{O} 31 \cdot \mathrm{L} 11$

\section{Introduction}

What type of "currency" do firms use when they trade intellectual property (IP)? Looking at the empirical evidence, it is not obvious that cash is the only method of payment. Rather, it seems that firms pay with their own IP in exchange for other

Patrick Herbst

patrick.herbst@stir.ac.uk

Eric Jahn

eric.jahn@ba-dresden.de

1 Stirling Management School, Accounting and Finance Division, University of Stirling, Stirling FK9 4LA, UK

2 University of Cooperative Education Dresden, Hans-Grundig-Str. 25, 01307 Dresden, Germany 
firms' technology. This means of exchange is particularly evident in the discussion of so-called cross-licensing agreements.

Put simply, cross-licensing implies granting reciprocal access to IP or patents by firms. Evidence suggests that cross-licensing is more than a simple, reciprocal seller-buyer-relation but is part of a common standard for technology transfer. For example, Anand and Khanna (2000) report that within the US manufacturing industry, $12.6 \%$ of licensing agreements are cross-licensing contracts. ${ }^{1}$ Cohen et al. (2000) observe that among the US manufacturing firms surveyed, $33.5 \%$ use patents on product innovations in cross-licensing.

Limiting trade in technology to reciprocal exchange can also be part of a longterm strategy. Intel's formerly proclaimed "IP-for-IP" strategy is a case in point. This strategy involved that Intel granted access to its IP only to firms who gave Intel access to their own IP (Shapiro 2001, 2004). Cohen et al. (2000, p. 29) report that survey "[r]espondents noted that firms are reluctant to sell their technology, but are willing to trade it only to firms that have valuable technology (intellectual property) to use as currency".

In this paper, we suggest that the means of exchange in the market for technology affect the R\&D activities of firms. We show that in an environment with trade restrictions (IP-for-IP/cross-licensing, or even no trade in technology) firm profits might increase as overinvestment in $R \& D$ is decreased. However, these trading restrictions come at the cost of forgone gains from trade when IP is distributed asymmetrically across firms. By providing a model of the trade-offs involved, our analysis shows that an IP-for-IP environment can be beneficial for firms as it balances R\&D overinvestment against gains from trade in technology.

The paper is organized as follows: Sect. 2 discusses the related literature. Section 3 lays out our general approach. Section 4 introduces the model. Section 5 analyzes R\&D competition under free trade, IP-for-IP, and no trade, and compares the outcomes under these environments when patent complementarities are present and when they are absent. Section 6 introduces specific extensions to the model and discusses policy implications. Section 7 concludes.

\section{Related Literature}

There exist many different reasons why firms might enter into cross-licensing agreements. $^{2}$ Technological necessities or threat from legal litigation might force firms to do so. In markets with highly fragmented technologies, cross-licensing agreements might also be considered a cost-effective means of IP exchange and a way of avoiding double marginalization. Similarly, firms might decide against (cross-)licensing for anti-competitive reasons, such as foreclosure of potential

\footnotetext{
1 This proportion increases to $20.1 \%$ within the Electronic and Electrical Equipment industry. For Japanese manufacturing firms, Nagaoka and Kwon (2006) report that $11.3 \%$ of licensing contracts between independent firms are cross-licensing contracts.

2 See, among others, Anand and Khanna (2000), Arora and Fosfuri (2003), Choi (2010), Fershtman and Kamien (1992), Galasso and Schankerman (2010), Grindley and Teece (1997), Layne-Farrar and Schmidt (2010), Lemley and Shapiro (2007), Shapiro (2001, 2004).
} 
rivals. ${ }^{3}$ Although we acknowledge these arguments, our aim is to highlight how IPfor-IP affects the nature of $R \& D$ competition and post-R\&D patent allocation, absent any post-patent competitive effects.

The aspect of reciprocity in access to technology is stressed strongly in several analyses of cross-licensing. For example, according to Grindley and Teece (1997, p. 23), "to obtain access to needed technologies, Hewlett-Packard needs patents to trade in cross-licensing agreements." The same authors report that IBM acquires necessary outside IP rights "primarily by trading access to its own patents, a process called 'cross-licensing'” (p. 15).

Referring to semiconductor firms, Hall and Ziedonis (2001, p. 107) argue that "many manufacturers had decided to "harvest' more patents from their R\&D ... to assist them in winning favorable terms in cross-licensing negotiations". In a similar way, The Economist (2005) writes that "[u]nless firms have patents of their own to assert so they can reach a cross-licensing agreement (often with money changing hands too), they will be in trouble." The relevance of using patents in negotiations (but not as a source of licensing revenues) is also stressed in the survey findings of Cohen et al. (2000).

These reports of firms' motivations to patent and cross-license raise the question why a firm's own IP (cross-licensing) is a different currency than cash (one-way licensing) when accessing outside technology. We contribute to the literature by highlighting why the type of currency (or other trading restrictions) in the market for technology might matter in the context of firms' R\&D activities. ${ }^{4}$ Our paper thus complements other papers that analyze the effects that licensing, cross-licensing, or patent litigation have on firms' R\&D investments (see, for example, Gallini and Winter 1985; Fershtman and Kamien 1992; Ménière and Parlane 2008).

Our model contains the features of a patent race and is therefore also closely related to the traditional patent race literature. The symmetric models in Loury (1979) and Lee and Wilde (1980) show that patent races among a fixed number of firms lead to overinvestment in R\&D compared to the cooperative solution. R\&D by one firm creates a negative externality on other firms' expected profits which results in cumulative R\&D expenditures that are too high from a social perspective. ${ }^{5} \mathrm{We}$ show that trading restrictions in the market for technology mitigate this negative externality problem. ${ }^{6}$

In contrast to traditional patent races, Fershtman and Kamien (1992) show that underinvestment might arise under strict patent complementarity and crosslicensing when firms are perfectly specialized in their R\&D. This potential

\footnotetext{
3 There is also a strand of the literature that studies the effect of licensing on competition (Shapiro 2003; Lerner and Tirole 2004) and litigation (Choi 2010). These analyses usually provide 'ex-post' analyses; i.e., they consider situations where firms already possess patents. Cross-licensing agreements (or patent pools as an extension thereof) naturally arise as agreements between patent owners.

4 In a more general context, Prendergast and Stole (1996) address the potential economic implications of monetary versus non-monetary trade (i.e. barter) in assets.

5 For a survey on patent race models, see Reinganum (1989).

6 Our analysis thus provides another illustration of the mechanisms behind the theory of second best (see Lipsey and Lancaster 1956). We are very grateful to the editor for pointing out this connection.
} 
underinvestment also features in our analysis. However, R\&D specialization arises endogenously in our model.

Our paper also relates to the literature that focuses on project choice in R\&D. One strand of this literature focuses primarily on the choice of risk that firms take in R\&D competition (e.g., Bhattacharya and Mookherjee 1986; Dasgupta and Maskin 1987; Cabral 2003; Gerlach et al. 2005; Anderson and Cabral 2007).

Other papers endogenize project choice when technologies are substitutes in the product market, either by considering sequential project choices (Cardon and Sasaki 1998) or by allocating resources across projects (Lin and Zhou 2013). Choi and Gerlach (2014), on the other hand, consider the sequential development of complementary technologies. Our paper adds to the literature by focusing on the simultaneous R\&D allocation across projects under alternative trading environments.

\section{General Approach}

We consider two firms and two R\&D projects. Both firms may engage in the same two R\&D projects. Each firm decides about its overall R\&D investment as well as the allocation across the two projects. The projects stochastically yield IP that can be commercialized, each in a different product market.

Firms differ in their ability to commercialize IP in the different product markets due to differences in assets that are complementary to innovations (e.g., in sales and marketing or in subsequent manufacturing processes; see Teece 1986, 2006). These differences enable them to capture gains from trade when a firm with a lower commercialization ability sells its IP to the one with higher ability with respect to a certain product market. At the same time, gains from trade also raise the incentives to pursue $\mathrm{R} \& \mathrm{D}$ in a project that is outside the firm's key market, thus increasing R\&D competition.

A further gain from trade arises from complementary features in the patents: While each patent is most valuable in its key market, combining its features with those of the other market's patent increases its value even further. This complementarity introduces gains from licensing a patent outside its key market and gives rise to cross-licensing arrangements.

To illustrate our set-up, consider two car companies: One focuses on sports cars (e.g., Porsche); and one focuses on family cars (e.g., Hyundai). Both firms may engage in research that improves aerodynamics or child safety. The sports car manufacturer is best suited to use the aerodynamics patent in its core market, while the child safety patent might add some value in that market. The sports car manufacturer might also use the child safety patent and enter the market for family cars, but would typically lack the capabilities to realize the patent's full value. The family car manufacturer, however, is able to reap the full market value of the safety technology, and may use the aerodynamics patent to enhance its cars' value. ${ }^{7}$

\footnotetext{
7 We are grateful to a referee for this example. An example from another industry would be the market for smart home appliances with firms such as Samsung or, with acquisition of Nest Labs, Google. As a
} 
The trading environment in the market for technology affects both the level and allocation of firms' R\&D expenditures. We show in particular that if firms differ sufficiently in their commercialization abilities, trade restrictions (both IP-for-IP and no trade in technology) result in firms' focusing on their core market, which lowers costly overinvestment in R\&D. Absent patent complementarities, this benefit comes at no costs. However, with patent complementarities, some gains from trade are forgone with trading restrictions. In this case, an IP-for-IP environment is optimal as it balances the benefit of more efficient investments against losses in gains from trade.

\section{Model}

Set-up We consider two firms $(i=1,2)$ that are engaged in two markets $(j=1,2)$. In each market, a firm can pursue a research project that stochastically yields at most one patent. ${ }^{8}$ The whole R\&D process is sufficiently uncertain such that the outcome is non-contractible. Hence, firms cannot write ex ante contracts for the new patent. The maximum stand-alone value of either patent is symmetric and given by $V$. In addition, each patent contains features that complement the other patent and thus enhances that patent's value by a factor $\gamma \geq 1$. While ownership of patent $j$ is necessary to realize its value in market $j$, having access to patent $i \neq j$ increases that value. $^{9}$

Firms can be heterogeneous with respect to their core market. Specifically, they differ in their commercialization abilities in the two markets. We assume that firm $i$ can fully exploit the value of patent $i$ (in market $i$ ) whereas it can only realize a fraction $\delta \in[0,1]$ of patent $j$ 's value in market $j$ (where $j \neq i$ ). For example, if firm 1 owned both patents (and absent any patent sale or licensing), it would realize $\gamma V$ in market 1 plus $\delta \gamma V$ in market 2 .

Trade in Technology Once firms have obtained patents they might want to trade them. By trading patents, firms can realize gains from trade for two reasons. First, given differences in commercialization abilities $(\delta<1)$, trade creates value when patents are reallocated to the firm with the highest commercialization ability. Second, the use of a patent in combination with the other generates value from complementary features (for $\gamma>1$ ).

We assume that the structure of transactions depends on the source of gains from trade. Specifically, in order to use patent $i$ in its original market $i$, a firm has to be the (sole) owner of the patent. Therefore, reallocation of a patent to a firm with higher commercialization ability is achieved via the sale of a patent. On the other

\footnotetext{
Footnote 7 continued

traditional producer of appliances, Samsung has more to gain from developments in the hardware or electronic components, whereas Google could profit more from software patents. At the same time, both companies could add further value by licensing each others' hardware/software patents.

${ }^{8}$ We consider the impact of additional patents in Sect. 6.1.

9 Our definition of complementarity is not based on technological necessity (as in, e.g., Fershtman and Kamien 1992; Layne-Farrar and Schmidt 2010; Choi and Gerlach 2014), but is based on the value added to a product by an additional patent (see also Lerner and Tirole 2004).
} 
hand, a transaction allowing another firm access to a patent to realize the value from complementary features takes place via a licensing agreement that restricts the use of patent $i$ to market $j \neq i$. ${ }^{10}$

Firms operate under one of three trading environments: In the first environment, labeled "free trade" (FT), firms can exchange patents without any restrictions. Therefore, firms can realize all gains from trade. We assume that firms bargain with equal bargaining power over the price of the patent(s) to be exchanged or licensed.

In the other two environments, firms are restricted in their trading opportunities. Under the terms of the "IP-for-IP" (IP) environment, firms are not able to use money for the purchase of a patent or license from another firm. Rather, a firm may only use its own IP as currency for the IP of the other firm. Typically, this is achieved via cross-licensing contracts. Contrary to the free trade case, firms might not be able to exploit all potential gains from trade under IP-for-IP.

No gains from trade are realized under the third trading environment, which is labeled "no trade" (NT). In this environment, trade in technology is not possible. Hence, firms can only use their patents themselves, even if they have limited value due to low commercialization abilities. We include this extreme environment not because it reflects observed trading environments, but rather to illustrate how the partial restriction of trade under IP-for-IP could be preferable over the two extreme cases of free trade and no trade.

Timing and Structure of the Analysis Within each trading environment, we consider firms' investment (and trading) decisions based on the following time structure:

$\mathrm{t}=0$ Firms simultaneously decide about their R\&D investments.

$\mathrm{t}=1$ Nature determines the allocation of patents (conditional on $\mathrm{R} \& \mathrm{D}$ expenditures).

$\mathrm{t}=2$ Trade takes place if the trading environment allows it. All payoffs are realized thereafter.

Our focus is on the level and allocation of R\&D investments by the two firms in the initial stage, given the trading environment in which they are present. For each trading environment, we analyze the subgame perfect equilibrium in investments and the resulting expected profits. We restrict the main analysis to symmetric Nash equilibria.

$R \& D$ Strategies and Costs In the initial stage of the model, firms decide about the unconditional probability of success in each project. If both firms are successful on a certain project, then each firm obtains the patent with probability $1 / 2$. Let the unconditional success probability of firm $i$ be $p_{i} \in[0,1]$ in its core market (for project $j=i$ ), and $q_{i} \in[0,1]$ in the other market (for project $j \neq i$ ). We assume that each firm's cost function is

\footnotetext{
${ }^{10}$ In a perfect contracting environment, both types of uses of a patent could be contracted upon via licensing contracts. In general, however, the risk of contractual mis-specification is greater when a patent is the core patent in a market than when it contains additional, complementary value. Therefore, full transfer of ownership is more suitable in the former case.
} 


$$
c\left(p_{i}, q_{i}\right)=-\ln \left(1-p_{i}\right)-\ln \left(1-q_{i}\right) .
$$

Notice that for $p_{i}, q_{i} \in[0,1], c\left(p_{i}, q_{i}\right) \geq 0 .{ }^{11} \mathrm{We}$ also assume $V \geq 16$, which eases the analysis of equilibria with interior solutions.

\section{Analysis}

\subsection{Post-trading Profits}

Generally, firms' profits depend on the pre-trade allocation of patents by nature and the trading environment, which determine the final allocation of patents. As a patent can be owned by at most one firm, let $\omega_{j} \in \Omega \equiv\{\emptyset, 1,2\}$ denote the post-R\&D, pretrade owner of patent $j$ (if $\omega_{j}=\emptyset$, no firm succeeded in developing a patent in market $j$ ). With three potential outcomes (firm 1 ownership, firm 2 ownership, or no patent) per market patent, there are nine possible pre-trade allocations of patents $\left(\omega_{1}, \omega_{2}\right)$. Let $p\left(\omega_{1}, \omega_{2}\right)$ be the probability of an allocation.

Similarly, let $\pi_{i}^{\Theta}\left(\omega_{1}, \omega_{2}\right)$ denote firm $i$ 's post-trade payoff from this allocation, which depends on the trading environment $\Theta \in\{F T, I P, N T\}$ : When there are no restrictions to trading technology, each firm will ex post own the patent it values most, plus a license to use the complementary patent if available. ${ }^{12}$ The price at which patents are traded or licensed is set such that the parties split the gains from trade equally. Under IP-for-IP, gains from trade can only be realized on a reciprocal basis. Under no trade, no gains from trade are realized.

Table 1 provides the probabilities and payoffs to the two firms for all possible patent allocations and environments. Consider for example allocation $(\emptyset, 1)$ : Firm 1 gains the patent for market 2 and values it at $\delta V$. As firm 2's valuation is higher, they trade (the patent is sold to firm 2) and split the gains, $(1-\delta) V$, equally under free trade. However, under IP-for-IP or no trade, there is no possibility to trade, so firm 1 uses the patent itself at the reduced value of $\delta V$.

In cases where both patents have been developed successfully, trade can generate value by both reallocating patents to firms with higher commercialization abilities and by allowing use of patents across markets to reap complementarity values. Consider for example allocation $(2,2)$ : Under free trade, firm 2 sells patent 1 to firm 1 (thus enabling firm 1 to enter market 1 exclusively), but also licenses patent 2 to firm 1 as a complementary patent. In addition, firm 2 retains a license to use patent 1 in its own market 2 to allow for the complementarity values to be realized. Under both IP-for-IP and no trade, firm 2 keeps both patents.

In general, when only one of the firms owns a patent or both patents, both IP-forIP and no trade yield the same payoffs. If, however, each firm owns a patent, IP-for-

\footnotetext{
11 Technically, the cost function is undefined for $p_{i}, q_{i}$ equal to 1 . We therefore assume $\lim _{p_{i}, q_{i} \rightarrow 1} c\left(p_{i}, q_{i}\right)=\infty$. This choice of a success probability, say $p$, at costs $-\ln (1-p)$ is equivalent to the choice of R\&D expenditures $x$ and modeling the success probability as $\left(1-e^{-x}\right)$, which has been used in prior literature (see, e.g., Kultti et al. 2007).

12 As ownership is required to access a market, there is no competition between firms within a market.
} 
Table 1 Patent allocations and payoffs

\begin{tabular}{|c|c|c|c|c|}
\hline \multirow[t]{2}{*}{$\left(\omega_{1}, \omega_{2}\right)$} & \multirow[t]{2}{*}{$\phi\left(\omega_{1}, \omega_{2}\right)$} & \multicolumn{3}{|l|}{$\pi_{i}\left(\omega_{1}, \omega_{2}\right)$} \\
\hline & & Free trade & IP-for-IP & No trade \\
\hline \multirow[t]{2}{*}{$(\emptyset, \emptyset)$} & \multirow[t]{2}{*}{$\left(1-p_{1}\right)\left(1-q_{2}\right)\left(1-q_{1}\right)\left(1-p_{2}\right)$} & $\pi_{1}=0$ & $\pi_{1}=0$ & $\pi_{1}=0$ \\
\hline & & $\pi_{2}=0$ & $\pi_{2}=0$ & $\pi_{2}=0$ \\
\hline \multirow[t]{2}{*}{$(1, \emptyset)$} & \multirow[t]{2}{*}{$\left(p_{1}\left(1-q_{2}\right)+\frac{1}{2} p_{1} q_{2}\right)\left(1-q_{1}\right)\left(1-p_{2}\right)$} & $\pi_{1}=V$ & $\pi_{1}=V$ & $\pi_{1}=V$ \\
\hline & & $\pi_{2}=0$ & $\pi_{2}=0$ & $\pi_{2}=0$ \\
\hline \multirow[t]{2}{*}{$(2, \emptyset)$} & \multirow{2}{*}{$\left(q_{2}\left(1-p_{1}\right)+\frac{1}{2} q_{2} p_{1}\right)\left(1-q_{1}\right)\left(1-p_{2}\right)$} & $\pi_{1}=\frac{1-\delta}{2} V$ & $\pi_{1}=0$ & $\pi_{1}=0$ \\
\hline & & $\pi_{2}=\frac{1+\delta}{2} V$ & $\pi_{2}=\delta V$ & $\pi_{2}=\delta V$ \\
\hline \multirow[t]{2}{*}{$(\emptyset, 2)$} & \multirow{2}{*}{$\left(1-p_{1}\right)\left(1-q_{2}\right)\left(p_{2}\left(1-q_{1}\right)+\frac{1}{2} q_{1} p_{2}\right)$} & $\pi_{1}=0$ & $\pi_{1}=0$ & $\pi_{1}=0$ \\
\hline & & $\pi_{2}=V$ & $\pi_{2}=V$ & $\pi_{2}=V$ \\
\hline \multirow[t]{2}{*}{$(\emptyset, 1)$} & \multirow[t]{2}{*}{$\left(1-p_{1}\right)\left(1-q_{2}\right)\left(q_{1}\left(1-p_{2}\right)+\frac{1}{2} q_{1} p_{2}\right)$} & $\pi_{1}=\frac{1+\delta}{2} V$ & $\pi_{1}=\delta V$ & $\pi_{1}=\delta V$ \\
\hline & & $\pi_{2}=\frac{1-\delta}{2} V$ & $\pi_{2}=0$ & $\pi_{2}=0$ \\
\hline \multirow[t]{2}{*}{$(1,1)$} & \multirow[t]{2}{*}{$\left(p_{1}\left(1-q_{2}\right)+\frac{1}{2} p_{1} q_{2}\right)\left(q_{1}\left(1-p_{2}\right)+\frac{1}{2} q_{1} p_{2}\right)$} & $\pi_{1}=\frac{3+\delta}{2} \gamma V$ & $\pi_{1}=(1+\delta) \gamma V$ & $\pi_{1}=(1+\delta) \gamma V$ \\
\hline & & $\pi_{2}=\frac{1-\delta}{2} \gamma V$ & $\pi_{2}=0$ & $\pi_{2}=0$ \\
\hline \multirow[t]{2}{*}{$(2,2)$} & \multirow[t]{2}{*}{$\left(q_{2}\left(1-p_{1}\right)+\frac{1}{2} q_{2} p_{1}\right)\left(p_{2}\left(1-q_{1}\right)+\frac{1}{2} q_{1} p_{2}\right)$} & $\pi_{1}=\frac{1-\delta}{2} \gamma V$ & $\pi_{1}=0$ & $\pi_{1}=0$ \\
\hline & & $\pi_{2}=\frac{3+\delta}{2} \gamma V$ & $\pi_{2}=(1+\delta) \gamma V$ & $\pi_{2}=(1+\delta) \gamma V$ \\
\hline \multirow[t]{2}{*}{$(2,1)$} & \multirow[t]{2}{*}{$\left(q_{1}\left(1-p_{2}\right)+\frac{1}{2} q_{1} p_{2}\right)\left(q_{2}\left(1-p_{1}\right)+\frac{1}{2} q_{2} p_{1}\right)$} & $\pi_{1}=\gamma V$ & $\pi_{1}=\gamma V$ & $\pi_{1}=\delta V$ \\
\hline & & $\pi_{2}=\gamma V$ & $\pi_{2}=\gamma V$ & $\pi_{2}=\delta V$ \\
\hline \multirow[t]{2}{*}{$(1,2)$} & \multirow[t]{2}{*}{$\left(p_{1}\left(1-q_{2}\right)+\frac{1}{2} p_{1} q_{2}\right)\left(p_{2}\left(1-q_{1}\right)+\frac{1}{2} q_{1} p_{2}\right)$} & $\pi_{1}=\gamma V$ & $\pi_{1}=\gamma V$ & $\pi_{1}=V$ \\
\hline & & $\pi_{2}=\gamma V$ & $\pi_{2}=\gamma V$ & $\pi_{2}=V$ \\
\hline
\end{tabular}

IP yields the same gains from trade as does free trade. For example, for allocation $(2,1)$, the two firms exchange the patents and cross-license them to enable the use of complementary features. However, under no trade, no exchange takes place, and firms only realize the limited value of a patent in their non-core market.

Lemma 1 Assume that there is at least one firm that invests in each market.

1. For $\delta<1$, firms forgo gains from trade under IP-for-IP, unless equilibrium investments under IP-for-IP yield $q_{1}=q_{2}=0$.

2. For $\delta<1$ and $\gamma=1$, firms forgo gains from trade under no trade, unless equilibrium investments under no trade yield $q_{1}=q_{2}=0$. For $\gamma>1$, firms always forgo gains from trade under no trade.

Proof The results follow from inspection of the payoffs in Table 1:

Part 1.: Comparing payoffs shows that for $\delta=1$, IP-for-IP and free trade yield identical payoffs for each pre-trade allocation. For $\delta<1$, payoffs under IP-for-IP are strictly lower than under free trade for $\left(\omega_{1}, \omega_{2}\right) \in\{(2, \emptyset),(\emptyset, 1),(1,1),(2,2)\}$. However, for $q_{1}=q_{2}=0$ these allocations never occur.

Part 2.: Comparing payoffs shows that, for $\gamma=1$ and $\delta<1$, post-trading profits under no trade are strictly lower than under free trade for $\left(\omega_{1}, \omega_{2}\right) \in\{(2, \emptyset),(\emptyset, 1)$, $(1,1),(2,2),(2,1)\}$. However, for $q_{1}=q_{2}=0$ these allocations never occur. For 
$\gamma>1$, profits under no trade are strictly lower than under free trade whenever patents have been successfully developed in both markets.

Lemma 1 shows that tougher trade restrictions lead to forgone gains from trade, unless both firms completely shun one of the markets. Under IP-for-IP, differences in commercialization abilities are the main drivers of forgone gains from trade: Firms are unable to reallocate patents whenever they are distributed asymmetrically. However, for symmetric allocations post-R\&D, cross-licensing enables them to realize the value of complementary patents. Under no trade, neither reallocation of patents nor patent complementarities may be realized.

\subsection{Equilibrium R\&D Investments and Profits}

Lemma 1 illustrates under which conditions trade restrictions impose costs on firms. For the trade restrictions to be beneficial to firms at all, these costs would have to be compensated by gains due to changes in the R\&D investment stage. Firm $i$ 's expected profit in the R\&D stage under trading environment $\Theta$ is

$$
E\left[\pi_{i}^{\Theta}\right]=\sum_{\omega_{1} \in \Omega} \sum_{\omega_{2} \in \Omega} p\left(\omega_{1}, \omega_{2}\right) \pi_{i}^{\Theta}\left(\omega_{1}, \omega_{2}\right)-c\left(p_{i}, q_{i}\right) .
$$

In the following, we first analyze equilibrium outcomes absent any patent complementarities $(\gamma=1)$ and then consider the effect of introducing complementarities.

Investments and Profits absent Patent Complementarities For $\gamma=1$, the two patents are not technologically linked. Moreover, under free trade the two research projects are not strategically linked with each other as trading of one patent is independent of the other. However, under IP-for-IP, the trade restrictions strategically interlink both research projects: The ability to trade a patent depends on the distribution of patents over both projects. For $\delta<1$, a firm might be forced to commercialize a patent at value $\delta V$ although trade would have been desirable. However, if the competing firm happens to have the other patent-that is, for allocation (2,1) —exchange is possible.

For benchmark purposes we first derive the optimal cooperative solution regarding the $\mathrm{R} \& \mathrm{D}$ investments. Joint profits are

$$
\begin{aligned}
E\left[\pi_{1}+\pi_{2}\right] & =V\left(2-\left(1-p_{1}\right)\left(1-q_{2}\right)-\left(1-q_{1}\right)\left(1-p_{2}\right)\right) \\
& +\sum_{k=1,2}\left[\ln \left(1-p_{k}\right)+\ln \left(1-q_{k}\right)\right] .
\end{aligned}
$$

This function is maximized if in each market (dropping firm subscripts)

$$
(1-p)(1-q)=\frac{1}{V}
$$

with the (cooperative) investment levels

$$
p^{\text {Coop }}=\frac{V-1}{V} \quad \text { and } \quad q^{\text {Coop }}=0
$$


as a specific solution to the joint optimization problem. We use the investments under the cooperative solution in order to compare the investment efficiency of equilibria under the various trading environments:

Definition 1 Overinvestment (underinvestment) arises in an equilibrium if firm 1 and 2's joint probability of obtaining a patent in a project is larger (smaller) than the joint success probability under the cooperative solution. The larger the difference between the two joint success probabilities, the larger the degree of overinvestment.

This definition illustrates that overinvestment does not arise because of R\&D duplication: condition (4) shows that the allocation of success probabilities across firms is not relevant for the cooperative solution. Rather, it is only the joint probability of successfully gaining a patent in a project that matters from a first-best view. ${ }^{13}$ With this definition, we now turn to firms' non-cooperative R\&D investment decisions.

\section{Lemma 2 Let $\gamma=1$.}

1. For $\delta=1$, all three trading environments yield the same set of equilibria.

2. Under free trade, the equilibrium regarding firms' $R \& D$ investments is unique and characterized by overinvestment. Investments and the degree of overinvestment are continuously increasing in $\delta$.

3. Under IP-for-IP, (1) there exists an $R \& D$ equilibrium that is characterized by overinvestment for all $\delta \in[0,1] ;$ (2) for all $\delta \in[0, \hat{\delta}]$ with $\hat{\delta} \equiv \frac{2}{V+1}$, there exists an additional equilibrium with $p^{I P}=\frac{V-1}{V}$ and $q^{I P}=0$. The latter equilibrium thus coincides with the cooperative solution.

4. Under no trade, the equilibrium in $R \& D$ investments is unique with investment levels continuous in $\delta$. For $\delta \in[0, \hat{\delta}]$, the equilibrium yields the cooperative solution; that $i s, p^{N T}=\frac{V-1}{V}$ and $q^{N T}=0 ;$ for $\delta>\hat{\delta}$, the equilibrium exhibits overinvestment.

\section{Proof See "Appendix 1.1".}

The first result in Lemma 2 is trivial: For $\delta=1$, firms are homogenous as they have identical commercialization abilities. There are no gains from trade; and consequently, trade or trade restrictions do not affect firm profits or investments.

Part 2. of the lemma establishes, for the free trade case, the standard result of $\mathrm{R} \& \mathrm{D}$ overinvestment in the patent race literature. For $\delta<1$, the 'patent race' is asymmetric as firms invest more in their core market than in their non-core market. At the same time, even for $\delta=0$, firms invest into their non-core market as they can still realize value from trading the non-core patent.

Part 3. of Lemma 2 shows that the strategic interrelation between both projects under IP-for-IP leads to multiple equilibria. One equilibrium exists over the full range of $\delta$ and results in overinvestment similar to the free trade equilibrium. The second equilibrium

\footnotetext{
13 The irrelevance of how the joint success probability is realized across the two firms arises from the specific cost function, and remains valid for the case of patent complementarities as well as the extensions in Sect. 6. While this feature eases the payoff comparisons across trading environments, duplication of effort could be introduced by adding project-specific fix costs for any non-zero success probability: Having firms focus on one project would then be the only jointly optimal solution.
} 
only exists if $\delta \leq \hat{\delta}$. Within this parameter range, it yields the same investment levels as the cooperative solution derived above. For $\delta$ increasing beyond $\hat{\delta}$, this cooperative equilibrium ceases to exist. Hence, there is a discontinuity in investments at $\delta=\hat{\delta}$, and the new equilibrium will result in R\&D overinvestment by the firms. ${ }^{14}$

The fourth part of the lemma shows that the no-trade restriction also allows the firms to achieve the cooperative solution. Hence, absent patent complementarities, both IPfor-IP and no trade yield the same equilibrium in $\mathrm{R} \& \mathrm{D}$ for $\delta \in[0, \hat{\delta}]$.

Combining the findings on equilibrium investments with the analysis of posttrading profits yields the following result:

\section{Proposition 1 Let $\gamma=1$.}

1. For $\delta \in[0, \hat{\delta}]$, there exist equilibria under both IP-for-IP and no trade that yield higher profits than the equilibrium under free trade.

2. There exists $\tilde{\delta}>\hat{\delta}$ such that for $\delta \in(\hat{\delta}, \tilde{\delta}]$, the no trade environment yields higher equilibrium profits than either free trade or IP-for-IP.

Proof Part 1.: By parts 3. and 4. of Lemma 2, there exist equilibria for $\delta \in[0, \hat{\delta}]$ that yield the jointly optimal investment levels with $q_{1}=q_{2}=0$. By Lemma 1 , the latter implies that under both IP-for-IP and no trade, firms do not forgo any gains from trade. Part 2.: Because of the continuity of profits and investments under no trade (part 4. of Lemma 2), expected profits under no trade converge to the level of the cooperative solution for $\delta$ approaching $\hat{\delta}$ from above. Because of the discontinuity at $\delta=\hat{\delta}$ of investments under IP-for-IP and the overinvestment results under IP-for-IP (for $\delta>\hat{\delta}$ ) and free trade (for any $\delta$ ), expected profits are strictly lower than the jointly optimal profits for any $\delta>\hat{\delta}$ under both free trade and IP-for-IP.

The key result of Proposition 1 is that, absent patent complementarities and for sufficiently heterogeneous commercialization abilities, trade restrictions can have a positive impact on firm profits. Specifically, trade restrictions reduce and even overcome the overinvestment problem in the firms' $R \& D$ competition. The equilibrium allocation of investments across firms results in each firm focusing on its core market. Under this specific allocation, no gains from trade are lost despite the trade restrictions.

For $\delta \leq \hat{\delta}$, both IP-for-IP and no trade yield the same equilibrium in R\&D and, because there is no value in cross-licensing, the same payoffs. Part 2. of Proposition 1 suggests that the no-trade environment might be preferable to the IP-for-IP environment for a specific range of commercialization abilities. However, we will show in the next step that this particular result does not hold once patent complementarities are introduced.

Investments and Profits under Patent Complementarities The key effect of feature complementarity is to increase the value of both patents existing. Therefore, firms' incentives to invest increase for both R\&D projects. Consequently, firms also

\footnotetext{
${ }^{14}$ In the following, we drop the discussion of the IP-for-IP equilibrium that exists over the full range of $\delta$. Numerical simulations show it to be inferior to the free trade equilibrium.
} 
have a stronger incentive to undertake research in both markets. The strength of this effect is now different under IP-for-IP and no trade. We show that the critical values of $\delta$ where firms focus only on one market in equilibrium under IP-for-IP (now labeled $\left.\hat{\delta}^{I P}\right)$ and no trade $\left(\hat{\delta}^{N T}\right)$ diverge.

An additional effect of patent complementarities is that, for free trade and IP-forIP, successful R\&D has a potential positive externality for the other firm: One firm's success raises the other patent's value if cross-licensing is agreed upon. This externality implies that the jointly optimal (cooperative) investment levels will differ from the equilibrium levels when only one firm is active in a project. ${ }^{15}$

\section{Proposition 2}

1. The cooperative solution under patent complementarities can be characterized by $p^{* \text { Coop }}>0$ (as given in Eq. (24) in the "Appendix") and $q^{* \text { Coop }}=0$.

2. For $\delta \in\left[0, \hat{\delta}^{I P}\right]$, there exists an equilibrium under IP-for-IP with investment levels $p^{*, I P}>0$ and $q^{*, I P}=0$.

3. For $\delta \in\left[0, \hat{\delta}^{N T}\right]$ and $\gamma \leq 1+\frac{2 V}{V^{2}-1}$, there exists an equilibrium under no trade with investment levels $p^{*, N T}>0$ and $q^{*, N T}=0$. For $\gamma>1+\frac{2 V}{V^{2}-1}$, any equilibrium under no trade has $p^{*, N T}>0$ and $q^{*, N T}>0$.

4. Under free trade, any equilibrium has $p^{*, F T}>0$ and $q^{*, F T}>0$.

5. Evaluated at $\gamma=1$, a marginal increase in $\gamma$ has the following effects:

(a) The critical level of $\delta$ where a firm invests only in one project in equilibrium under IP-for-IP or no trade decreases. The decrease is higher under no trade than under IP-for-IP: $0>\frac{d \hat{\delta}^{P}}{d \gamma}>\frac{d \hat{\delta}^{N T}}{d \gamma}$.

(b) The cooperative investment level, $p^{* \text { Coop }}$, increases more than the singlefirm IP-for-IP equilibrium investment level, $p^{*, I P}$, while the single-firm no trade equilibrium level, $p^{*, N T}$, remains unchanged: $\frac{d p^{\text {Coop }}}{d \gamma}>\frac{d p^{*, I P}}{d \gamma}>$ $\frac{d p^{*, N T}}{d \gamma}=0$.

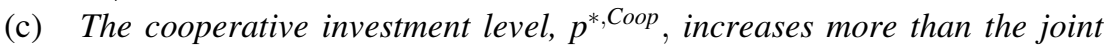
probability of obtaining a patent under free trade: $\frac{d p^{\text {Coop }}}{d \gamma}>\frac{d\left(p^{*, F T}+q^{*, F T}-p^{*, F T} q^{*, F T}\right)}{d \gamma}>0$

\section{Proof See "Appendix 1.2"}

Two patterns arise with the introduction of patent complementarities: First, equilibria with firms concentrating their investments on their core market under IPfor-IP and no trade still exist. However, the range of parameters that sustain these equilibria is now smaller under no trade than under IP-for-IP (see parts 3. and 5.(a) of Proposition 2). In particular, once patent complementarities are sufficiently pronounced under no trade, firms will remain active in both markets for any level of

\footnotetext{
${ }^{15}$ The externality also creates further interaction effects between the two firms' investment decisions, which hinder the derivation of full analytical solutions. The subsequent analysis thus focuses on the marginal effects of introducing patent complementarities.
} 
commercialization ability (part 3.). In this environment, the only way to realize patent complementarities is to be successful in both projects. Under IP-for-IP, however, patent complementarities can be realized via cross-licensing.

The second effect of complementarities is to induce a difference between the cooperative investment levels and the investment levels when firms only invest in their core market. Specifically, such equilibria result in firms' underinvesting in R\&D compared to the cooperative solution under no trade and IP-for-IP (see part 5.(b)). Moreover, this underinvestment is more pronounced under no trade than under IP-for-IP. Again, the effect comes from the benefits of cross-licensing, which creates a positive externality from investments. Under IP-for-IP, this externality is not taken into account by the firms, and is never realized under no trade.

Under free trade, the externality from investments also affects the investments relative to the cooperative solution: Part 5.(c) of Proposition 2 shows that the degree of overinvestment under free trade decreases with patent complementarities even while individual investment levels increase.

Generally, the results of Proposition 2 suggest that when patent complementarities exist and firms differ sufficiently in commercialization abilities, IP-for-IP and cross-licensing yield higher profits for firms: For $\gamma$ close to one, IP-for-IP then results in no cost from forgone trade (because firms focus on their core market), and investment levels are close to the cooperative solution. Hence, firms' expected profits are also close to the jointly optimal level.

Further numerical analyses illustrate the case for IP-for-IP and further strengthen the conjectures from Proposition 2. ${ }^{16}$ Figure 1 presents, for all trading environments, equilibrium investment levels and firm profits normalized by the respective jointly optimal level for $V=16$ and different values of $\gamma$. Specifically, the two top panels in Fig. 1 show the equilibrium probability of any firm obtaining a patent in a market, while the two lower panels depict expected profits in equilibrium. The lefthand column depicts equilibrium outcomes at $\delta=0$, and the right-hand column depicts outcomes at $\delta=\hat{\delta}^{I P}$.

The figure illustrates how the outcomes under IP-for-IP and the no trade environment diverge for $\gamma>1$. At $\delta=0$, both environments result in underinvestment as $\gamma$ increases, with the underinvestment greater under no trade than IP-for-IP initially. In combination with the forgone gains from trade under no trade, firm profits decrease strongly, while profits under IP-for-IP remain very close to the cooperative profit level. ${ }^{17}$

As $\gamma$ increases above the threshold given in part 3. of Proposition 2, both firms remain active in both markets for any $\delta \geq 0$ under no trade. This induces an increase in investment levels, as can be seen in the upward kink in the top left panel. While this at first appears to reduce the underinvestment problem, the effect of forgone gains from trade is more pronounced, and the overall effect on firm profits is even more negative.

\footnotetext{
16 Only some of the results in Proposition 2 can be shown to hold for general values of $\gamma$. A broad set of parameters tested by us in numerical simulations supports our results.

17 Numerically, it can be shown that firm profits decrease relative to the cooperative level under IP-forIP. However, the decrease is too small to be visible in the figure.
} 

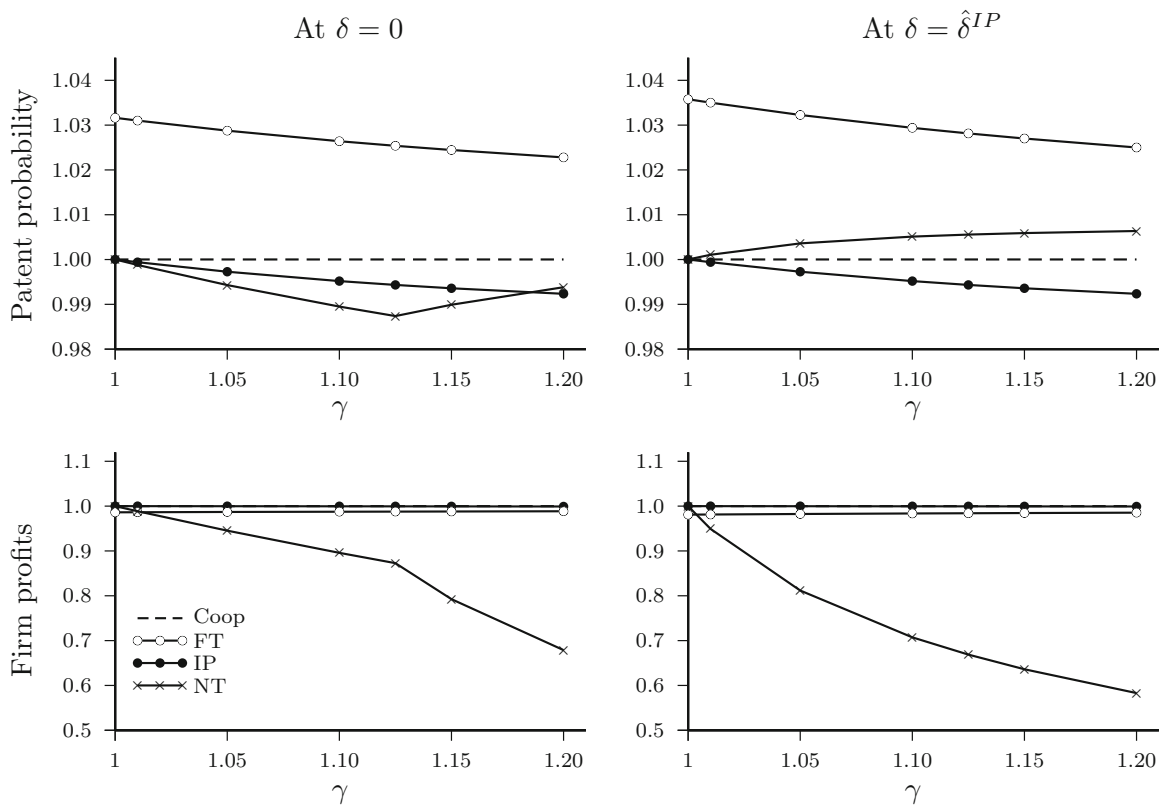

Fig. 1 Equilibrium outcomes (relative to jointly optimal values) (numerical results for $\mathrm{V}=16$ )

Overall, our results show that the IP-for-IP trading environment induces beneficial re-alignment of R\&D investments (for firms that differ in commercialization abilities), while enabling firms to continue to reap the benefits of crosslicensing. And although the more severe trading restrictions under no trade might also accomplish these improvements in special cases (absent patent complementarities), our analysis shows that the benefits of the intermediate level of trading restrictions under IP-for-IP are more robust.

\section{Extensions and Discussion}

In the following, we extend our model to incorporate features that are common in the market for technology: (1) the use of multiple patents in cross-licensing; and (2) markets of different sizes. ${ }^{18}$ Our aim is to see whether the key mechanisms of our model carry over to these settings. To simplify the analysis, we ignore the no-trade environment and drop the assumption of patent complementarities, setting $\gamma=1$. Despite this simplification, the extended model is too complex under IP-for-IP to be solved analytically, so we resort to presenting the results via numerical simulations. ${ }^{19}$ We then discuss policy implications of our analysis.

\footnotetext{
${ }^{18} \mathrm{We}$ are grateful to the editor and a reviewer for suggesting these extensions.

19 Details of the underlying analysis are available from the corresponding author.
} 


\subsection{Additional Patents}

Typically, cross-licensing agreements involve portfolios of patents on both sides of the agreement (see, e.g., Grindley and Teece 1997; Shapiro 2001). We therefore now assume that each firm owns an additional patent that enhances the value of the patent in its non-core market. Specifically, firm 1 (firm 2) owns a patent that allows the owner of the patent for market 2 (market 1) to increase the maximum value of that market by a factor $\alpha \geq 1$.

For simplicity, we assume that firms simply hold these patents, as endogenizing the development of such patents (and thus patent portfolios) is beyond the scope of our paper. Moreover, we only introduce additional patents in firms' non-core market, as additional patents in their core markets would only strengthen the case for focusing investments on core markets.

Introducing additional patents strengthens the potential gains from trade in technology. The left-hand part of Table 2 presents the post-trading payoffs under both free trade and IP-for-IP, with changes to the base model highlighted by shaded cells. Apart from the obvious scaled market value $\alpha V$, a firm now also benefits from trade in technology when the other firm already owns the patent in its core market.

Consider, for example, allocation $(1, \emptyset)$ : Although firm 1 already owns patent 1 , there are further gains from trade by licensing the additional patent from firm 2 , and the payoffs under free trade show the shared gains from trade. Under IP-for-IP, however, no trade takes place in this case, and firm 1 only realizes the market value $V$ and gains from trade are lost. In contrast, when each firm successfully develops a patent (allocations $(2,1)$ and $(1,2)$ ), gains from trade are also realized under IP-forIP. $^{20}$

The introduction of additional patents raises the value of obtaining the core market patents, and thus raises the jointly optimal investments as well as those under free trade. Our numerical simulations show that although the overinvestment problem prevails under free trade, the extent of the overinvestment decreases as the value-enhancement parameter $\alpha$ increases.

Under IP-for-IP, an equilibrium exists for sufficiently large differences in commercialization abilities $\left(\delta \leq \hat{\delta}^{\text {add }}\right.$, with $\hat{\delta}^{\text {add }} \geq \hat{\delta}$ and increasing in $\alpha$ ), such that each firm only invests in its core market. However, for $\alpha>1$, IP-for-IP now yields underinvestments in $\mathrm{R} \& \mathrm{D}$, as firms do not realize the benefits of the additional patents whenever only one firm succeeds in getting a patent.

The effect of additional patents on firm profits under the two trading environment is presented in the top panels of Fig. 2. It shows firm profits normalized by the jointly optimal level of profits under the two trading environments for various values of $\alpha$ and two different values of $\delta\left(\delta=0\right.$ and $\left.\delta=\hat{\delta}^{\text {add }}\right)$. For values of $\alpha$ close enough to one, IP-for-IP continues to yield higher firm profits than does free trade. As the benefits of the additional patents increase, both the underinvestment problem and lost gains from trade reduce profits under IP-for-IP, while the overinvestment

\footnotetext{
${ }^{20}$ In the $(1,2)$ case, cross-licensing only involves the cross-licensing of the additional patents, whereas the $(2,1)$ case implies cross-licensing of patent portfolios.
} 
Table 2 Extensions: patent allocations and payoffs (shaded cells indicate changes from the base model)

\begin{tabular}{|c|c|c|c|c|}
\hline \multirow[t]{2}{*}{$\left(\omega_{1}, \omega_{2}\right)$} & \multicolumn{2}{|c|}{$\begin{array}{l}\text { Additional Patents } \\
\pi_{i}\left(\omega_{1}, \omega_{2}\right)\end{array}$} & \multicolumn{2}{|c|}{$\begin{array}{l}\text { Asymmetric Markets } \\
\pi_{i}\left(\omega_{1}, \omega_{2}\right)\end{array}$} \\
\hline & Free trade & IP-for-IP & Free trade & IP-for-IP \\
\hline$(\emptyset, \emptyset)$ & $\begin{array}{l}\pi_{1}=0 \\
\pi_{2}=0\end{array}$ & $\begin{array}{l}\pi_{1}=0 \\
\pi_{2}=0\end{array}$ & $\begin{array}{l}\pi_{1}=0 \\
\pi_{2}=0\end{array}$ & $\begin{array}{l}\pi_{1}=0 \\
\pi_{2}=0\end{array}$ \\
\hline$(1, \emptyset)$ & $\begin{array}{l}\pi_{1}=\frac{1+\alpha}{2} V \\
\pi_{2}=\frac{\alpha-1}{2} V\end{array}$ & $\begin{array}{l}\pi_{1}=V \\
\pi_{2}=0\end{array}$ & $\begin{array}{l}\pi_{1}=\beta V \\
\pi_{2}=0\end{array}$ & $\begin{array}{l}\pi_{1}=\beta V \\
\pi_{2}=0\end{array}$ \\
\hline$(2, \emptyset)$ & $\begin{array}{l}\pi_{1}=\frac{1-\delta}{2} \alpha V \\
\pi_{2}=\frac{1+\delta}{2} \alpha V\end{array}$ & $\begin{array}{l}\pi_{1}=0 \\
\pi_{2}=\delta \alpha V\end{array}$ & $\begin{array}{l}\pi_{1}=\frac{1-\delta}{2} \beta V \\
\pi_{2}=\frac{1+\delta}{2} \beta V\end{array}$ & $\begin{array}{l}\pi_{1}=0 \\
\pi_{2}=\delta \beta V\end{array}$ \\
\hline$(\emptyset, 2)$ & $\begin{aligned} \pi_{1} & =\frac{\alpha-1}{2} V \\
\pi_{2} & =\frac{1+\alpha}{2} V\end{aligned}$ & $\begin{array}{l}\pi_{1}=0 \\
\pi_{2}=V\end{array}$ & $\begin{array}{l}\pi_{1}=0 \\
\pi_{2}=V\end{array}$ & $\begin{array}{l}\pi_{1}=0 \\
\pi_{2}=V\end{array}$ \\
\hline$(\emptyset, 1)$ & $\begin{array}{l}\pi_{1}=\frac{1+\delta}{2} \alpha V \\
\pi_{2}=\frac{1-\delta}{2} \alpha V\end{array}$ & $\begin{array}{l}\pi_{1}=\delta \alpha V \\
\pi_{2}=0\end{array}$ & $\begin{array}{l}\pi_{1}=\frac{1+\delta}{2} V \\
\pi_{2}=\frac{1-\delta}{2} V\end{array}$ & $\begin{array}{l}\pi_{1}=\delta V \\
\pi_{2}=0\end{array}$ \\
\hline$(1,1)$ & $\begin{array}{l}\pi_{1}=\frac{2 \alpha+1+\delta \alpha}{2} V \\
\pi_{2}=\frac{2 \alpha-1-\delta \alpha}{2} V\end{array}$ & $\begin{array}{l}\pi_{1}=(1+\delta \alpha) V \\
\pi_{2}=0\end{array}$ & $\begin{array}{l}\pi_{1}=\frac{2 \beta+1+\delta}{2} V \\
\pi_{2}=\frac{1-\delta}{2} V\end{array}$ & $\begin{array}{l}\pi_{1}=(\beta+\delta) V \\
\pi_{2}=0\end{array}$ \\
\hline$(2,2)$ & $\begin{array}{l}\pi_{1}=\frac{2 \alpha-1-\delta \alpha}{2} V \\
\pi_{2}=\frac{2 \alpha+1+\delta \alpha}{2} V\end{array}$ & $\begin{array}{l}\pi_{1}=0 \\
\pi_{2}=(1+\delta \alpha) V\end{array}$ & $\begin{array}{l}\pi_{1}=\frac{1-\delta}{2} \beta V \\
\pi_{2}=\frac{2+(1+\delta) \beta}{2} V\end{array}$ & $\begin{array}{l}\pi_{1}=0 \\
\pi_{2}=(\delta \beta+1) V\end{array}$ \\
\hline$(2,1)$ & $\begin{array}{l}\pi_{1}=\alpha V \\
\pi_{2}=\alpha V\end{array}$ & $\begin{array}{l}\pi_{1}=\alpha V \\
\pi_{2}=\alpha V\end{array}$ & $\begin{array}{l}\pi_{1}=\frac{(1-\delta) \beta+1+\delta}{2} V \\
\pi_{2}=\frac{(1+\delta) \beta+1-\delta}{2} V\end{array}$ & $\begin{array}{l}\pi_{1}=\beta V \\
\pi_{2}=V\end{array}$ \\
\hline$(1,2)$ & $\begin{array}{l}\pi_{1}=\alpha V \\
\pi_{2}=\alpha V\end{array}$ & $\begin{array}{l}\pi_{1}=\alpha V \\
\pi_{2}=\alpha V\end{array}$ & $\begin{array}{l}\pi_{1}=\beta V \\
\pi_{2}=V\end{array}$ & $\begin{array}{l}\pi_{1}=\beta V \\
\pi_{2}=V\end{array}$ \\
\hline
\end{tabular}

problem under free trade decreases. As a consequence, for sufficiently high values of $\alpha$, firms will prefer free trade to the IP-for-IP environment.

Overall, the introduction of additional patents suggests that, once these patents are highly value-enhancing, cross-licensing might not be the most preferred means of trade in technology. On the other hand, for only limited value-enhancements, our results about the benefits of cross-licensing not only hold but also apply to a larger set of parameters with regard to the commercialization ability. Hence, under additional patents, cross-licensing would be preferred by even more firms than in the base model with single patents.

\subsection{Asymmetric Markets}

So far, the model assumed that the two firms are symmetric in all respects. However, as markets often differ in size, we now ask whether differently sized markets affect the benefits of IP-for-IP. ${ }^{21}$ To introduce asymmetric markets, we scale the maximum value of market 1 by factor $\beta \geq 1$.

\footnotetext{
21 An earlier version of the paper considered asymmetries in commercialization abilities. Our results are robust to such an extension, details of which are available from the corresponding author.
} 

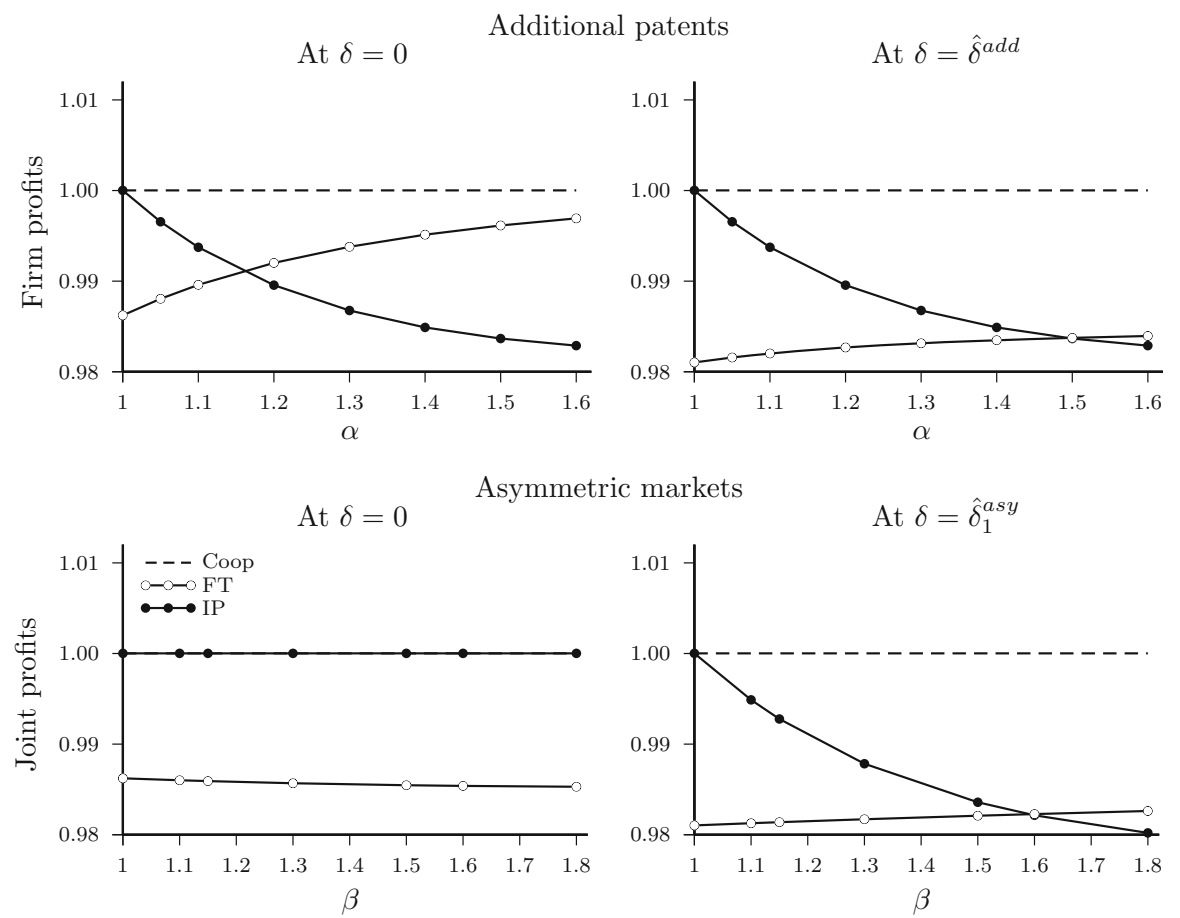

Fig. 2 Equilibrium payoffs (relative to jointly optimal values) in model extensions (numerical results for $\mathrm{V}=16)$

The last two columns in Table 2 provide the post-trading payoff structures when the value that is attainable in market 1 is increased. Of course, owning patent 1 yields higher profits for both firms, and the gains from trade in this patent also increase with the value of the market. An additional effect is that firm 2 now loses from trade under IP-for-IP (relative to the symmetric case): As we assume that IPfor-IP remains a non-monetary exchange even under this asymmetric structure, there are no side-payments that are included under the $(2,1)$ allocation. Hence, firm 2 exchanges the higher-value patent 1 for patent 2 without the compensation it would receive under free trade. ${ }^{22}$

Because of the larger size of market 1 , the jointly optimal investment into project 1 increases, and so does both firms' investment under free trade. Cooperative and free trade investments into project 2, on the other hand, remain unaffected by the change in market 1's size. Under IP-for-IP, these changes now result in different threshold values of firms' commercialization abilities such that firms confine their investments to their core market. For $\delta \in\left[0, \hat{\delta}_{2}^{a s y m}\right]$, both firms focus their investments on their respective core markets. As there are no benefits

\footnotetext{
22 Absent side-payments, firm 2 would not be willing to give away patent 2 if $\delta>1 / \beta$. However, this restriction does not bind in our numerical simulations, allowing us to ignore side-payments.
} 
from complementary patents, these equilibria under IP-for-IP reproduce the jointly optimal investment levels, and hence maximize joint profits.

However, there now exists a second threshold under IP-for-IP, $\hat{\delta}_{1}^{\text {asym }} \geq \hat{\delta}_{2}^{\text {asym }}$, such that for $\delta \in\left(\hat{\delta}_{2}^{a s y m}, \hat{\delta}_{1}^{a s y m}\right]$, firm 1 focuses investments on its core market, while firm 2 continues to invest in both projects. In this equilibrium, the cooperative solution is still realized in market 2 , but there are efficiency losses in market 1 because of overinvestments and forgone gains from trade. The greater is the size increase of market $1, \beta$, the more pronounced are these efficiency losses. For $\delta$ sufficiently close to (but below) $\hat{\delta}_{1}^{\text {asym }}$, there exists a critical parameter $\beta$ such that joint profits under IP-for-IP fall below joint profits under free trade.

The two lower panels of Fig. 2 illustrate the two cases that result with the introduction of asymmetric markets. The lower left panel illustrates the case of $\delta=0$, where both firms focus investments on their respective core markets under IP-for-IP. Since such an equilibrium reproduces the cooperative solution, joint profits under IP-for-IP are higher than under free trade irrespective of the size parameter $\beta$.

The lower right panel depicts joint profits for $\delta=\hat{\delta}_{1}^{a s y m}$ : at a level of commercialization ability where only firm 1 focuses investments on its core market, while firm 2 invests in both projects. The figure shows how joint profits under IP-for-IP fall below the level under the jointly optimal solution. With increasing $\beta$, the lost gains from trade and the cost from overinvestments overcompensate the benefits of the market 2 investments at the cooperative level. For sufficiently high values of $\beta$, the free trade environment yields higher joint profit levels than does IP-for-IP.

It is important to note that Fig. 2 provides results only for joint profits, which matter mostly under welfare or industry considerations. Firm-level profits provide further information about the costs and benefits of IP-for-IP. Most importantly, our numerical results suggest that the benefits of IP-for-IP mostly accrue to firm 1. For any numerical case tested, as long as $\delta \leq \hat{\delta}_{1}^{a s y m}$, firm 1 would always gain from IPfor-IP relative to free trade. Firm 2, however, only gains from IP-for-IP for sufficiently low values of $\beta$. These differences in profits arise from the fact that firm 1 , by focusing on its core market, either partly or fully crowds out firm 2's investments in the larger, more profitable, market 1 .

In sum, introducing differences in market size does not affect the key trade-offs of our model significantly. However, it introduces asymmetries in investment equilibria, which can reduce the earlier discussed benefits of IP-for-IP, thus making the free trade environment overall more profitable. At the firm level, different market sizes also give rise to asymmetries in payoffs and differences in the desirability of trading restrictions.

\subsection{Policy Implications}

The set-up of our analysis focuses on firm profits and the choice of investments under different trading restrictions. To simplify the analysis, post-R\&D competition 
and the social value of the patents in question have been ignored. This precludes a formal welfare analysis of firms' behavior. Nevertheless, the analysis allows for some qualifications with regard to welfare and policy implications.

Consider first the investment levels and the private versus social value of patents. If the firms' private value of the patents reflects the social value of patents, thentrivially-firm behavior is optimal also from a welfare point of view. Similarly, for a social value of the patents higher than the private value, investment levels under free trade might be too high or too low. In the latter case, trade restrictions that limit $R \& D$ competition have an unambiguously negative level effect.

Differences between the private and social value of patents might arise from the competitive environment. For example, the differences in commercialization ability in our model might not stem from complementary assets but from market power, with each firm an existing incumbent in its core market. Then, the firms' focusing of $\mathrm{R} \& \mathrm{D}$ on core markets under IP-for-IP might be excessive from a social point of view, as it bolsters dominant firms.

Similarly, an IP-for-IP trading environment might limit entry into markets and thus lower competition in the long run. This is most evident when R\&D might also be provided by smaller research outlets. Absent own commercialization abilities, IPfor-IP precludes these smaller firms from entering a market, and confines R\&D to large firms. ${ }^{23}$ In such a case, any positive effects from improving the efficiency in R\&D investments among larger firms would have to be weighted against negative effects on small firms' entry.

In our analysis, we also assumed that even under the cross-licensing of complementary patents, the two firms do not compete in each others' markets. This can be achieved, for example, by prohibiting the use of patents in the licensor's core market. Such usage restrictions are common practice and frequently discussed in the antitrust literature (see, e.g., Gilbert 2008). It is important to note that in our model, firms also use such restrictions under free trade. The restrictions are not solely an issue in one trading environment, and might even arise under one-sided licensing. Shapiro (2003) and Lerner and Tirole (2004) provide a discussion of post-R\&D competition and licensing arrangements.

Lastly, when involving intellectual property and new technologies, antitrust policy has to strike a balance between the promotion of competition and the protection of intellectual property to induce innovation (Gilbert 2008). Hence, even if the benefits of an IP-for-IP environment result in some form of enhanced market power, the resulting private gains might induce firms to pursue more innovative projects. Overall, absent further analysis, it is difficult to identify clearly a positive or negative welfare effect of trading restrictions and cross-licensing.

\footnotetext{
${ }^{23}$ Shapiro (2001) discusses such a potential negative effect in his analysis of Intel's IP-for-IP strategy and its challenge by antitrust authorities. Shapiro (2004) and the FTC's documentation at http://www.ftc. gov/os/caselist/d9288.shtm provide further detail.
} 


\section{Concluding Remarks}

In this paper, we argue that trading restrictions in the market for technology can have an impact on R\&D competition among firms. In its simplest set-up, the model has two firms that allocate their research budget over two R\&D projects. Firms' R\&D technologies are homogeneous across both projects. However, firms have heterogeneous commercialization abilities with regard to the output of the two projects, and the two projects yield additional complementary value gains. Both aspects potentially allow the firms to realize potential gains from trade after the completion of R\&D activity.

We analyze the effects that arise from trade restrictions that restrain firms from using cash when trading technology. The model shows the trade-offs that are involved with the restriction of trade to IP-for-IP (and cross-licensing). On the one hand, firms forgo potential gains from trade as in some cases desirable trade does not take place because it would require cash transactions. On the other hand, these trade restrictions drive a wedge between the two projects and thus reduce overinvestment in $\mathrm{R} \& \mathrm{D}$.

The analysis shows that equilibria exist under an IP-for-IP environment where both firms concentrate their R\&D effort on their core market. Specifically, the model suggests that IP-for-IP restrictions raise profits as long as the difference between firms' commercialization abilities as well as patent complementarities are sufficiently high. In sum, we show that the way IP is traded has an impact on the creation of technology. The paper thus gives an ex-ante oriented explanation why cash might be a different currency than IP in the market for technology.

By focusing our analysis on the investment stage of the $R \& D$ process, we consciously ignored several important aspects. For example, a more specific modeling of the post-patent competition stage and the role of small research firms can be informative for issues of competition policy. Moreover, patent infringements and litigation affect the post-R\&D allocation of patents and thus affect the trading outcomes. As the trading outcomes change, so will firms' optimal R\&D investments. All these aspects lend themselves to future analysis.

Acknowledgments We owe thanks to Francis Bloch, Matthias Blonski, Chloé le Coq, Guido Friebel, Orkhan Hasanaliyev, Michael Kosfeld, Christian Laux, Ulf von Lilienfeld-Toal, Volker Nocke, Heiner Schumacher, Konrad Stahl, Michael Raith, Michael Waldman, Uwe Walz, Lawrence White (the editor), two anonymous reviewers, as well as conference and seminar participants in Copenhagen, Frankfurt, Gerzensee, Guanajuato, Halifax, Mannheim, Strasbourg, and Washington for helpful comments. Financial support from the European Commission (Grant CIT5-CT-2006-028942) is gratefully acknowledged.

Open Access This article is distributed under the terms of the Creative Commons Attribution 4.0 International License (http://creativecommons.org/licenses/by/4.0/), which permits unrestricted use, distribution, and reproduction in any medium, provided you give appropriate credit to the original author(s) and the source, provide a link to the Creative Commons license, and indicate if changes were made. 


\section{Appendix 1}

\section{Appendix 1.1: Proof of Lemma 2}

Part 1. Inspection of the payoffs in Table 1 shows that for $\gamma=\delta=1$, the three environments yield identical payoffs for each pre-trade allocation.

Part 2. Under free trade, the first order conditions with respect to $p_{i}$ and $q_{i}$ are

$$
\begin{gathered}
\frac{\partial \pi_{i}^{F T}}{\partial p_{i}}=\frac{V}{4}\left(1-p_{i}\right)\left(4-(3-\delta) q_{j}\right)-1=0 \\
\frac{\partial \pi_{i}^{F T}}{\partial q_{i}}=\frac{V}{4}\left(1-q_{i}\right)\left(2-p_{j}\right)(1+\delta)-1=0,
\end{gathered}
$$

where $i \neq j$. The unique symmetric solution (on the interval $[0,1]$ ) is

$$
\begin{aligned}
& p^{F T}=1-\frac{\sqrt{V^{2}(1+\delta)^{4}+32 V(1+\delta)^{2}+64(1-\delta)^{2}}-V(1+\delta)^{2}-8(1-\delta)}{2 V(1+\delta)^{2}} \\
& q^{F T}=1-\frac{\sqrt{V^{2}(1+\delta)^{4}+32 V(1+\delta)^{2}+64(1-\delta)^{2}}-V(1+\delta)^{2}+8(1-\delta)}{2 V(1+\delta)(3-\delta)} .
\end{aligned}
$$

For $V \geq 3$ both solutions yield values within $[0,1]$.

Consider next the joint probability of obtaining a patent in one of the projects, $1-\left(1-p^{F T}\right)\left(1-q^{F T}\right)=p^{F T}+q^{F T}-p^{F T} q^{F T}$. Total differentiation yields

$$
\frac{d\left[p^{F T}+q^{F T}-p^{F T} q^{F T}\right]}{d \delta}=\left(1-q^{F T}\right) \frac{d p^{F T}}{d \delta}+\left(1-p^{F T}\right) \frac{d q^{F T}}{d \delta} .
$$

Because

$$
\frac{d p^{F T}}{d \delta}=\frac{\delta\left(1-p^{F T}\right)\left(1-q^{F T}\right)\left(2-p^{F T}\right)+(1+\delta)\left(2-p^{F T}\right)}{\left(4-(3-\delta) q^{F T}\right)\left(2-p^{F T}\right)(1+\delta)+\delta(1+\delta)\left(1-p^{F T}\right)\left(1-q^{F T}\right)}>0
$$

and

$$
\frac{d q^{F T}}{d \delta}=\frac{\left(1-q^{F T}\right)\left(4-(3-\delta) q^{F T}+4\left(1-p^{F T}\right)\left(1-q^{F T}\right)\right)}{\left(4-(3-\delta) q^{F T}\right)\left(2-p^{F T}\right)(1+\delta)+\delta(1+\delta)\left(1-p^{F T}\right)\left(1-q^{F T}\right)}>0
$$

$\mathrm{R} \& \mathrm{D}$ investments are increasing in $\delta$, and hence $\frac{d\left[p^{F T}+q^{F T}-p^{F T} q^{F T}\right]}{d \delta}>0$. Finally, compare the level of the joint probability of obtaining a patent in the free trade case 
for $\delta=0$ with the cooperative level: $1-\left(1-\left.p^{F T}\right|_{\delta=0}\right)\left(1-\left.q^{F T}\right|_{\delta=0}\right)>1-(1-$ $\left.p^{\text {Coop }}\right)\left(1-q^{\text {Coop }}\right)$ if

$$
\frac{\left(\sqrt{V^{2}+32 V+64}-V\right)^{2}-64}{12 V^{2}}<\frac{1}{V},
$$

which is true if $V>3$. As this implies overinvestment at the lower boundary of the joint patent probability, there is overinvestment for all $\delta \in[0,1]$ under free trade. Part 3. First order conditions under IP-for-IP are

$$
\begin{gathered}
\frac{\partial \pi_{i}^{I P}}{\partial p_{i}}=\frac{V}{4}\left(1-p_{i}\right)\left(4-q_{j}\left(2+(1-\delta) q_{i}\left(2-p_{j}\right)\right)\right)-1=0 \\
\frac{\partial \pi_{i}^{I P}}{\partial q_{i}}=\frac{V}{4}\left(1-q_{i}\right)\left(2-p_{j}\right)\left(2 \delta+(1-\delta) q_{j}\left(2-p_{i}\right)\right)-1=0 .
\end{gathered}
$$

As the proof that there exists an equilibrium over the full range of $\delta$ that results in overinvestment is rather extensive, it is omitted here and made available upon request from the corresponding author. Here, we show that for $\delta \leq \hat{\delta}$, there exists an equilibrium which yields the cooperative solution.

A symmetric equilibrium with firm $i$ active only in market $i$ (with $p_{1}=p_{2}=p^{m}$ ) exists if

$$
\begin{aligned}
& \left.\frac{\partial \pi_{i}^{I P}}{\partial p_{i}}\right|_{q_{1}=q_{2}=0, p_{1}=p_{2}=p^{m}}=0 \\
& \left.\frac{\partial \pi_{i}^{I P}}{\partial q_{i}}\right|_{q_{1}=q_{2}=0, p_{1}=p_{2}=p^{m}} \leq 0
\end{aligned}
$$

are satisfied. Using (14), (16) yields $p^{m}=\frac{V-1}{V}$, and hence (17) is fulfilled if $\delta \leq \frac{2}{V+1} \equiv \hat{\delta}$. For $\delta \in[0, \hat{\delta}]$, the cooperative solution is thus also an equilibrium under IP-for-IP.

Part 4. Under no trade, first order conditions with respect to $p_{i}$ and $q_{i}$ are

$$
\begin{gathered}
\frac{\partial \pi_{i}^{N T}}{\partial p_{i}}=\frac{V}{2}\left(1-p_{i}\right)\left(2-q_{j}\right)-1=0 \\
\frac{\partial \pi_{i}^{N T}}{\partial q_{i}}=\frac{V}{2} \delta\left(1-q_{i}\right)\left(2-p_{j}\right)-1=0 .
\end{gathered}
$$


The unique symmetric equilibrium (on the interval $[0,1]$ ) is

$$
\begin{aligned}
& p^{N T}=1-\frac{\sqrt{16 \delta+(\delta(V+2)-4)^{2}}-\delta V-2(1+\delta)}{2 \delta V} \\
& q^{N T}=1-\frac{\sqrt{16 \delta+(\delta(V+2)-4)^{2}}+\delta V-2(1+\delta)}{2 \delta V}
\end{aligned}
$$

for $\delta>\hat{\delta}$. At $\delta=\hat{\delta},(20)$ and (21) yield $p^{N T}=\frac{V-1}{V}$ and $q^{N T}=0$-i.e. the cooperative solution, which is also the equilibrium for $\delta<\hat{\delta}$.

Finally, for $\delta \geq \hat{\delta}$,

$$
\frac{d\left(p^{N T}+q^{N T}-q^{N T} q^{N T}\right)}{d \delta}=\frac{\left(1-p^{N T}\right)\left(2-p^{N T}\right)\left(1-q^{N T}\right)}{\delta\left(3-p^{N T}-q^{N T}\right)}>0
$$

which implies overinvestment in equilibrium if $\delta>\hat{\delta}$.

\section{Appendix 1.2: Proof of Proposition 2}

Part 1. Differentiating joint profits $\left(\pi_{1}+\pi_{2}\right)$ with respect to a firm's two investments $p_{i}$ and $q_{i}$ results in the identical first-order condition

$$
\left(1-p_{i}\right)\left(1-q_{i}\right)\left(1+2 q_{j}\left(1-p_{j}\right)(\gamma-1)+2 q_{j}(\gamma-1)\right)=\frac{1}{V} .
$$

Dropping subscripts, we set $q=0$ and solve for the symmetric solution:

$$
p^{*, \text { Coop }}=\frac{3 V-2 V \gamma-\sqrt{V} \sqrt{8+V-8 \gamma-4 V \gamma+4 V \gamma^{2}}}{2(2 V \gamma-2 V)} .
$$

Parts 2. and 3. We first derive the "monopoly" investment levels $p^{*, \Theta}$ and critical values $\hat{\delta}^{\Theta}$ where a firm $i$ exits market $j \neq i$ : Solving

$$
\left.\frac{\partial \pi_{i}^{\Theta}}{\partial p_{i}}\right|_{q_{1}=q_{2}=0, p_{1}=p_{2}=p}=0
$$

for $p$ yields $p^{*, \Theta}$. This can only be an equilibrium if

$$
\left.\frac{\partial \pi_{i}^{\Theta}}{\partial q_{i}}\right|_{p_{1}=p_{2}=p^{*, \Theta}, q_{1}=q_{2}=0} \leq 0
$$

which yields the condition $\delta \leq \hat{\delta}^{\Theta}$. For $\Theta \in\{I P, N T\}$, these steps result in

$$
p^{*, I P}=\frac{V \gamma+\sqrt{V} \sqrt{4-4 \gamma+V \gamma^{2}}-2 V}{2(V \gamma-V)}
$$




$$
\begin{gathered}
\hat{\delta}^{I P}=\frac{2\left(V \gamma-\sqrt{V} \sqrt{4-4 \gamma+V \gamma^{2}}\right)}{(\gamma-1)\left(2+V \gamma+\sqrt{V} \sqrt{4-4 \gamma+V \gamma^{2}}\right)} \\
p^{*, N T}=\frac{V-1}{V} \\
\hat{\delta}^{N T}=\frac{\gamma-1+2 V-V^{2}(\gamma-1)}{1-\gamma+V+V^{2} \gamma} .
\end{gathered}
$$

By L'Hôpital's rule, one can show that for $\gamma=1, p^{*, C o o p}=p^{*, I P}=p^{*, N T}=\frac{V-1}{V}$ and $\hat{\delta}^{I P}=\hat{\delta}^{N T}=\hat{\delta}$. In addition, $\hat{\delta}^{I P}>0$ for any $\gamma \geq 1$, while $\hat{\delta}^{N T} \geq 0$ only holds if

$$
\gamma \leq 1+\frac{2 V}{V^{2}-1}
$$

Hence, for $\gamma>1+\frac{2 V}{V^{2}-1}$, an equilibrium with firms only investing in their core market is not sustainable under no trade.

Part 4. By following the same approach as in (25) and (26) for $\Theta=F T$, we can derive the following critical value of $\delta$ supporting an equilibrium with firms investing in their core market only:

$$
\hat{\delta}^{F T}=-\frac{V \gamma^{2}-2+3 \sqrt{V} \sqrt{4-4 \gamma+V \gamma^{2}}+\gamma\left(2-5 V+\sqrt{V} \sqrt{4-4 \gamma+V \gamma^{2}}\right)}{(\gamma-1)\left(2+V \gamma+\sqrt{V} \sqrt{4-4 \gamma+V \gamma^{2}}\right)} .
$$

For $\gamma=1$, this reduces to $\hat{\delta}^{F T}=\frac{3-V}{V+1}<0$ for $V>3$. For $\gamma>1$, only the sign of the numerator in (32) needs to be determined (the denominator is always positive). Hence, to show that $\hat{\delta}^{F T}<0$, we require, after transforming the numerator,

$$
V \gamma(1-\gamma)+2(\gamma-1)-4 V \gamma+(3+\gamma) \sqrt{V^{2} \gamma^{2}-4 V(\gamma-1)}>0
$$

Dropping the first (positive) term, this condition can be transformed into the sufficient condition

$$
V(\gamma-1)\left[(\gamma-1)\left(V \gamma^{2}-\frac{4}{V}\right)+4\left(2 V \gamma^{2}-\gamma^{2}-2 \gamma-9\right)\right]>0 .
$$

The second (and last) term in brackets is increasing in $\gamma$ for $\gamma \geq 1$, and is positive at $\gamma=1$ for $V>6$. Hence, $\hat{\delta}^{F T}<0$ for all $\gamma \geq 1$, and there exists no equilibrium with firms investing only in their core market. 
Part 5. For part (a), differentiating $\hat{\delta}^{I P}$ and $\hat{\delta}^{N T}$ with respect to $\gamma$ at $\gamma=1$ yields

$$
\begin{gathered}
\left.\frac{d \hat{\delta}^{I P}}{d \gamma}\right|_{\gamma=1}=-2 \frac{2 V^{2}-1-V}{V(V+1)^{2}}<0 \\
\left.\frac{d \hat{\delta}^{N T}}{d \gamma}\right|_{\gamma=1}=-\frac{V^{2}+2 V-3}{V+V^{2}}<0 \\
\left.\frac{d\left(\hat{\delta}^{I P}-\hat{\delta}^{N T}\right)}{d \gamma}\right|_{\gamma=1}=\frac{V^{3}-V^{2}+V-1}{V(V+1)^{2}}>0 .
\end{gathered}
$$

For part (b), differentiating $p^{*, C o o p}, p^{*, I P}$ and $p^{*, N T}$ with respect to $\gamma$ at $\gamma=1$ yields

$$
\begin{gathered}
\left.\frac{d p^{*, \text { Coop }}}{d \gamma}\right|_{\gamma=1}=2 \frac{V-1}{V^{2}}>0 \\
\left.\frac{d p^{*, I P}}{d \gamma}\right|_{\gamma=1}=\frac{V-1}{V^{2}}>0 \\
\left.\frac{d p^{*, N T}}{d \gamma}\right|_{\gamma=1}=0 .
\end{gathered}
$$

For part (c), using the first-order conditions in the free trade environment, we derive the following comparative static results in a symmetric equilibrium:

$$
\begin{gathered}
\left.\frac{d p^{*, F T}}{d \gamma}\right|_{\gamma=1}=\frac{V}{4}\left(1-p^{*, F T}\right)^{2}\left(4 p^{*, F T}\left(1-q^{*, F T}\right)^{2}\right. \\
\left.+q^{*, F T}\left(6-5 q^{*, F T}+\delta\left(2-q^{*, F T}\right)\right)\right)>0 \\
\left.\frac{d q^{*, F T}}{d \gamma}\right|_{\gamma=1}=\frac{V}{4}\left(1-q^{*, F T}\right)^{2}\left(4 q^{*, F T}\left(1-p^{*, F T}\right)+p^{*, F T}\left(2-p^{*, F T}\right)(1+\delta)\right. \\
\left.+4\left(1-p^{*, F T}\right)\left(1-q^{*, F T}\right)\right)>0 .
\end{gathered}
$$

Hence, the joint probability of obtaining a patent under free trade increases in $\gamma$ at $\gamma=1$. 
Finally, for the difference between the cooperative and free trade (joint) probability of obtaining a patent, we get

$$
\begin{aligned}
& \left.\frac{d^{2}\left(p^{*, \text { Coop }}-\left(p^{*, F T}+q^{*, F T}-p^{*, F T} q^{*, F T}\right)\right)}{d \gamma d \delta}\right|_{\gamma=1} \\
& \quad=-\frac{V}{4}(1-p)(1-q)(p(2-p)(1-q)+q(1-p)(2-q))<0 .
\end{aligned}
$$

Hence, we consider the difference at $\delta=1$, where the symmetric equilibrium (with $\gamma=1$ ) yields $p^{*, F T}=q^{*, F T}=\frac{3 V-\sqrt{V(V+8)}}{2 V}$ :

$$
\begin{gathered}
\left.\frac{d\left(p^{*, \text { Coop }}-\left(p^{*, F T}+q^{*, F T}-p^{*, F T} q^{*, F T}\right)\right)}{d \gamma}\right|_{\gamma=1, \delta=1} \\
=\frac{2 V^{2}+20 V+14-(2 V+10) \sqrt{V^{2}+8 V}}{V^{2}}>0,
\end{gathered}
$$

where for $V \geq 16$ the sign of the numerator can be shown to be positive. Since the difference in patent probabilities increases in $\gamma$ at $\delta=1$ and $\gamma=1$, it increases even more for lower values of $\delta$.

\section{References}

Anand, B. N., \& Khanna, T. (2000). The Structure of Licensing Contracts. Journal of Industrial Economics, 48(1), 103-135.

Anderson, A., \& Cabral, L. M. B. (2007). Go for broke or play it safe? Dynamic competition with choice of variance. The RAND Journal of Economics, 38(3), 593-609.

Arora, A., \& Fosfuri, A. (2003). Licensing the Market for Technology. Journal of Economic Behavior \& Organization, 52(2), 277.

Bhattacharya, S., \& Mookherjee, D. (1986). Portfolio choice in research and development. The RAND Journal of Economics, 17(4), 594-605.

Cabral, L. M. B. (2003). R\&D competition when firms choose variance. Journal of Economics \& Management Strategy, 12(1), 139-150.

Cardon, J. H., \& Sasaki, D. (1998). Preemptive search and R\&D clustering. The RAND Journal of Economics, 29(2), 324-338.

Choi, J. P. (2010). Patent pools and cross-licensing in the shadow of patent litigation. International Economic Review, 51(2), 441-460.

Choi, J. P., \& Gerlach, H. (2014). Selection biases in complementary R\&D projects. Journal of Economics \& Management Strategy, 23(4), 899-924.

Cohen, W. M., Nelson, R. R., \& Walsh, J. P. (2000). Protecting their intellectual assets: Appropriability conditions and why U.S. manufacturing firms patent (or not). NBER working paper.

Dasgupta, P., \& Maskin, E. (1987). The simple economics of research portfolios. Economic Journal, 97(387), 581-595.

Fershtman, C., \& Kamien, M. I. (1992). Cross licensing of complementary technologies. International Journal of Industrial Organization, 10(3), 329-348.

Galasso, A., \& Schankerman, M. (2010). Patent thickets, courts, and the market for innovation. The RAND Journal of Economics, 41(3), 472-503.

Gallini, N. T., \& Winter, R. A. (1985). Licensing in the theory of innovation. The RAND Journal of Economics, 16(2), 237-252.

Gerlach, H. A., Rønde, T., \& Stahl, K. (2005). Project choice and risk in R\&D. The Journal of Industrial Economics, 53(1), 53-81. 
Gilbert, R. J. (2008). Competition policy for intellectual property. In P. Buccirossi (Ed.), Handbook of antitrust economics, chap. 14 (pp. 519-542). Cambridge, MA: MIT Press.

Grindley, P. C., \& Teece, D. J. (1997). Managing intellectual capital: Licensing and cross-licensing in semiconductors and electronics. California Management Review, 39(2), 8-41.

Hall, B. H., \& Ziedonis, R. H. (2001). The patent paradox revisited: An empirical study of patenting in the U.S. semiconductor industry, 1979-1995. The RAND Journal of Economics, 32(1), 101-128.

Kultti, K., Takalo, T., \& Toikka, J. (2007). Secrecy versus patenting. The RAND Journal of Economics, $38(1), 22-42$.

Layne-Farrar, A., \& Schmidt, K. M. (2010). Licensing complementary patents: "Patent trolls," market structure, and "excessive royalties". Berkeley Technology Law Journal, 25(2), 1121-1143.

Lee, T., \& Wilde, L. L. (1980). Market structure and innovation: A reformulation. The Quarterly Journal of Economics, 94(2), 429-436.

Lemley, M. A., \& Shapiro, C. (2007). Patent holdup and royalty stacking. Texas Law Review, 85(7), 1991-2049.

Lerner, J., \& Tirole, J. (2004). Efficient patent pools. American Economic Review, 94(3), 691-711.

Lin, P., \& Zhou, W. (2013). The effects of competition on the R\&D portfolios of multiproduct firms. International Journal of Industrial Organization, 31(1), 83-91.

Lipsey, R. G., \& Lancaster, K. (1956). The general theory of second best. Review of Economic Studies, 24(1), 11-32.

Loury, G. C. (1979). Market structure and innovation. The Quarterly Journal of Economics, 93(3), 395-410.

Ménière, Y., \& Parlane, S. (2008). Innovation in the shadow of patent litigation. Review of Industrial Organization, 32, 95-111.

Nagaoka, S., \& Kwon, H. U. (2006). The incidence of cross-licensing: A theory and new evidence on the firm and contract level determinants. Research Policy, 35(9), 1347-1361.

Prendergast, C., \& Stole, L. A. (1996). Non-monetary exchange within firms and industry. NBER working papers 5765 .

Reinganum, J. F. (1989). The timing of innovation: Research, development, and diffusion. In R. Schmalensee \& R. Willig (Eds.), Handbook of industrial organization. Amsterdam: Elsevier.

Shapiro, C. (2001). Navigating the patent thicket: Cross licenses, patent pools, and standard setting. In A. B. Jaffe, J. Lerner, \& S. Stern (Eds.), Innovation policy and the economy (Vol. 1, pp. 119-150). Berkeley: MIT Press for the National Bureau of Economic Research.

Shapiro, C. (2003). Antitrust limits to patent settlements. The RAND Journal of Economics, 34(2), $391-411$.

Shapiro, C. (2004). Technology cross-licensing practices: FTC v. Intel (1999). In J. Kwoka, E. John, \& L. J. White (Eds.), The antitrust revolution: Economics, competition, and policy (pp. 350-372). Berkeley: Oxford University Press.

Teece, D. J. (1986). Profiting from technological innovation: Implications for integration, collaboration, licensing and public policy. Research Policy, 15(6), 285-305.

Teece, D. J. (2006). Reflections on profiting from innovation. Research Policy, 35(8), 1131-1146.

The Economist. (2005). A survey of patents and technology. The Economist, October 222005. 